\title{
Urinary infection caused by Micrococcus subgroup 3
}

\author{
HELEN KERR \\ From the Department of Microbiology, United Bristol Hospitals
}

SYNOPSIS The laboratory findings and clinical presentations in urinary infections in 23 nurses, 10 융 caused by Micrococcus subgroup 3 and 13 by Escherichia coli, were studied, and the symptoms and possible predisposing factors compared. There were no important differences between the two $\vec{N}$ groups. The infections caused by Micrococcus subgroup 3 were symptomatically severe, as were those caused by Escherichia coli.

'Coagulase-negative staphylococci' are often found in urine specimens as contaminants from the urethra, introitus, or skin. It is now well established, however, that similar organisms may infect the urinary tract (Torres Pereira, 1962; Mitchell, 1964; Gallagher, Montgomerie, and North, 1965; Person, Yu, and Washington, 1969; Bailey, Gower, Roberts, and De Wardener, 1971). The problem of elucidating the pathogenic role of these bacteria was simplified by the introduction of Baird-Parker's classification (1963) which divides the Micrococcaceae, on the basis of biochemical characters, into subgroups of Staphylococcus and Micrococcus. Infections in patients whose resistance is lowered by catheterization or by underlying urinary tract abnormality are caused by a variety of coagulase-negative strains, commonly Baird-Parker's Staphylococcus subgroups II and V (Mitchell, 1968) and sometimes by Staphylococcus aureus (coagulase-positive) (Baird-Parker's Staphylococcus subgroup 1). Infections of the urinary tract in healthy women, however, were shown by Mitchell (1968) to be characteristically caused by Micrococcus subgroup 3 . It has been suggested that some factor in the urinary tract acts selectively in favour of micrococci and in particular of subgroup 3 (Roberts, 1967). It is interesting to note that Staphylococcus aureus, the most pathogenic member of the Micrococcaceae at other sites, rarely infects the undamaged urinary tract. Mitchell (1968) showed that micrococcal infections caused pyuria and other signs and symptoms of acute inflammation of the urinary tract but there have been no reports comparing the clinical features and the severity of the infections with those due to Escherichia coli in previously healthy young women.

Received for publication 8 August 1973.

\section{Subjects and Methods}

The patients were nurses who attended the nurses' sick bay of the United Bristol Hospitals with symptoms of acute urinary infection between June 1971 and January 1972 (inclusive). One urine specimeo only was available from each patient as antibiotis treatment was started as soon as one sample was obtained. All Micrococcus subgroup 3 and Escherichia coli infections during this time were included. Fresh or refrigerated midstream specimens of urine were examined by microscopy and by culture on MacConkey agar (on which micrococci and Escherichia coli grew freely). Semiquantitative culture was performed by a standard loop technique and bacterial counts exceeding $10^{5}$ colony-forming units per millilitre were considered significant. The centrifuged deposit was examined and more than 10 leucocytes per high-power field were considered as significant pyuria (Albuquerque, Forster, Salles, and Cury, 1970). Gram-positive cocci (other than streptococci) were investigated for novobiocin resistance, a characteristic property of micrococci (Alder, Brown, and Mitchell, 1966) and for coagulase production. Coagulase-negative, novobiocin-resistant cultures were later further identified by Baird-Parker's $\widetilde{N}$ methods (1963). Lactose-fermenting, Gram-negative bacilli were identified by the methods of Cowan and Steel (1965). As soon as the provisional diagnosis was made, the names of the patients, but not the identity of the infecting organisms, were reported to the author who interviewed the patients and completed a standard questionnaire.

\section{Results}

The micrococcal infections were characterized by the 
presence of significant pyuria, and by bacterial counts clearly in excess of $10^{5}$ colony-forming units per millilitre. The urine white cell count varied from 10 to 20 cells per high-power field (HPF) in two cases, 20 to 50 per HPF in three cases, 50 to 100 cells per HPF in two cases, 100 to 200 cells per HPF in one case, and more than 200 cells in two cases. The bacterial counts were mostly in the range $10^{6}$ to $10^{7}$ per millilitre. During the period of the investigations no 'doubtful' counts, between $10^{3}$ and $10^{5}$ per millilitre, of micrococci were encountered in urines from the nurses' sick bay.

Twenty-three patients were studied, 10 with Micrococcus subgroup 3 and 13 with Escherichia coli infections. All the patients were women between 18 and 24 years old. The infections responded quickly to appropriate antibiotic therapy based on sensitivity tests, but the long-term results were not studied. The symptoms, including the severity of diurnal and nocturnal frequency, are shown in table I. The prevalence of factors of possible aetiological importance is shown in table II.

The two patients with Escherichia coli infections who had been catheterized had known congenital renal tract abnormalities and histories of repeated urinary infections. One woman had not been catheterized since childhood; the other had developed the reported infection immediately after catheterization. No patient with micrococcal infection was known to have a urinary tract abnormality. Only three women in this group had suffered previous infections; two had experienced only one previous episode and the third, eight previous infections, all directly related to sexual intercourse. Nine patients in the Escherichia coli group had suffered previous infections and six of these had had more than one past episode.

\begin{tabular}{|c|c|c|}
\hline \multirow[t]{2}{*}{ Symptom } & $\begin{array}{l}\text { Micrococcus Subgroup } 3 \\
\text { Infection (10 patients) }\end{array}$ & $\begin{array}{l}\text { E. coli Infection } \\
\text { (13 Patients) }\end{array}$ \\
\hline & No. of Patients & No. of Patients \\
\hline $\begin{array}{l}\text { Urgency } \\
\text { Incontinence } \\
\text { Urethral burning } \\
\text { Suprapubic pain } \\
\text { Loin pain } \\
\text { Macroscopic } \\
\text { haematuria } \\
\text { Mean maximal } \\
\text { diurnal frequency } \\
\text { Mean maximal } \\
\text { nocturnal } \\
\text { frequency }\end{array}$ & $\begin{array}{l}9(90 \%) \\
2(20 \%) \\
9(90 \%) \\
4(40 \%) \\
6(60 \%) \\
3(30 \%) \\
16\end{array}$ & $\begin{array}{r}12(92 \%) \\
4(31 \%) \\
10(77 \%) \\
5(38 \%) \\
8(62 \%) \\
4(31 \%) \\
19\end{array}$ \\
\hline
\end{tabular}

Table I Symptoms and severity of diurnal and nocturnal frequency in Micrococcus subgroup 3 and E. coli urinary infections.

\section{Discussion}

Until recently 'coagulase-negative staphylococci' isolated from urine and often reported as Staphylococcus albus have generally been considered to be contaminants. The present study confirms the observation of Mitchell and others that some of these organisms, notably those belonging to Micrococcus subgroup 3, can cause severe urinary tract infection. The infections resembled those due to Escherichia coli in the prevalence and severity of the usual symptoms and in their association with possible aetiological factors. Although the number of patients was small, the proportion of micrococcal infections was remarkably high, being almost equal to that of Escherichia coli infections. It has been reported that 'coagulase-negative staphylococcus' urinary infections outside hospitals occur in outbreaks whereas the incidence within hospital does

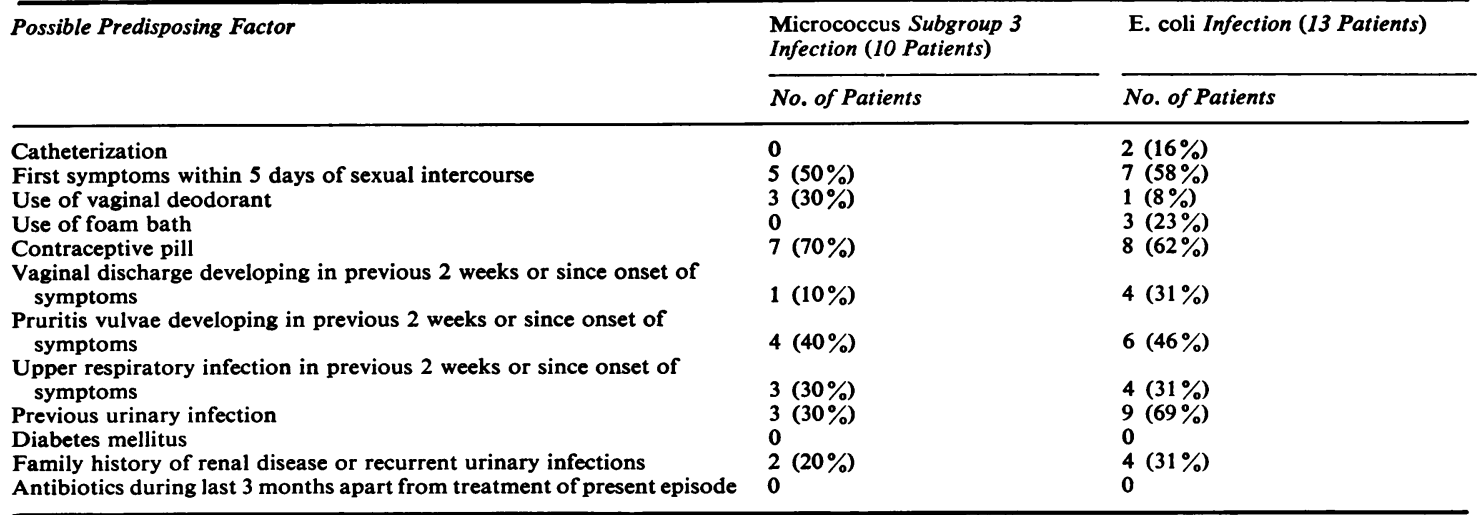

Table II Prevalence of factors of possible aetiological importance in Micrococcus subgroup 3 and $\mathrm{E}$. coli urinary infections 
not vary (Maskell, 1971). It is impossible to assess the relevance of this observation to nurses. Further studies are needed to elucidate the pathogenesis of micrococcal urinary infections, the subsequent history, and the possibility that they might cause renal disease.

I wish to thank Professor W. A. Gillespie and Dr D. C. E. Speller, of the Department of Microbiology, Dr D. G. H. Sylvester, Medical Officer to the Staff Health Service, and Miss E. H. L. Duncan, Senior Lecturer in Medical Statistics, University of Bristol, for their advice, Mrs M. Stephens for technical assistance, and the nurses of the United Bristol Hospitals for their cooperation.

\section{References}

Albuquerque, Paulo, F., Forster, Rodolpho, F., Salles, Osmar, and Cury, Carlos, A. (1970). Urinary infection: Review of 16,154 consecutive patients. J. Urol., 103, 205-209.
Alder, V. G., Brown, A. M., and Mitchell, R. G. (1966). The tellurite reactions of coagulase negative staphylococci and micrococci. J. appl. Bact., 29, 304-307.

Bailey, R. R., Gower, P. E., Roberts, A. P., and De Wardener, H. E. (1971). Prevention of urinary tract infection with low dose nitrofurantoin. Lancet, 2, 1112-1114.

Baird-Parker, A. C. (1963). A classification of micrococci and staphylococci based on physiological and biochemical tests. J. gen. Microbiol., 30, 409-427.

Cowan, S. T., and Steel, K. J. (1965). Manual for the Identification of Medical Bacteria. Cambridge University Press, Cambridge.

Gallagher, D. J. A., Montgomerie, J. Z., and North, J. D. K. (1965). Acute infections of the urinary tract and the urethral syndrome in general practice. Brit. med. J., 1, 622-626.

Maskell, R. M. (1971). Urinary infection by coagulase-negative staphylococci. Lancet, 2, 1258-1259.

Mitchell, R. G. (1964). Urinary tract infections due to coagulasenegative staphylococci. J. clin. Path., 17, 105-106.

Mitchell, R. G. (1968). Classification of Staphylococcus albus strains isolated from the urinary tract. J. clin. Path., 21, 93-96.

Person, D. A., Yu, Pauline, K. W., and Washington, J. A. III (1969). Characterisation of Micrococcaceae isolated from clinical sources. Appl. Microbiol., 18, 95-97.

Roberts, A. P. (1967). Micrococcaceae from the urinary tract in pregnancy. J. clin. Path., 20, 631-632.

Torres Pereira, A. (1962). Coagulase-negative strains of staphylococcus possessing antigen 51 as agents of urinary infection. J. clin. Path., 15, 252-253. 